\title{
Editorial
}

\section{Construindo saberes em Psicologia e Educação: a teia do conhecimento e o tempo da travessia}

Temos a imensa satisfação de compartilhar com a comunidade científica mais um número da Paidéia: Cadernos de Psicologia e Educação, agora disponível na Scientific Eletronic Library Online (SciELO), na qual passa a ser reconhecida como Paidéia (Ribeirão Preto). Como é do conhecimento geral, a SciELO (www.scielo.br) é uma biblioteca eletrônica virtual que abrange uma coleção selecionada de periódicos científicos brasileiros.

$\mathrm{O}$ mérito pelo êxito de mais uma edição da revista, que ora vem à lume, deve ser dividido com os autores, consultores e leitores, bem como o apoio obtido do Conselho Nacional de Desenvolvimento Científico e Tecnológico (CNPq) e do SIBI - Sistema Integrado de Bibliotecas da Universidade de São Paulo.

A indexação da Paidéia na SciELO tem facilitado o acesso ao conteúdo da revista, incorporando a consulta on line às práticas correntes dos pesquisadores e profissionais, o que é compatível com os atuais recursos proporcionados pela era da informação globalizada. Sabemos que a produção de saber em qualquer área científica só se completa quando os frutos gerados são divulgados e compartilhados com a comunidade que sustenta esse processo de construção da teia do conhecimento.

Nesse sentido, manifestamos nossa esperança de que o conhecimento consolidado nos artigos possa contribuir para o desempenho científico e profissional de nossos colegas que atuam nos mais diferentes contextos, considerando também a repercussão e o impacto potencial que esse saber pode ter em sua teia social e cultural.

A maior visibilidade conquistada pela revista tem gerado resultados auspiciosos. Sabemos que estamos em plena travessia. Nos bastidores da redação respiramos uma atmosfera de frescor, que nos inspira a trabalhar com entusiasmo e nos faz evocar Fernando Pessoa: "Há um tempo em que é preciso abandonar as roupas usadas que já têm a forma de nossos corpos e esquecer os nossos caminhos que nos levam sempre aos mesmos lugares. É o tempo da travessia. E se não ousarmos fazê-la teremos ficado para sempre à margem de nós mesmos".

Observa-se um crescimento da demanda, comprovado pelo crescente número de artigos submetidos por pesquisadores oriundos de todo o território nacional, assim como de outros países, à apreciação da Comissão e Conselho Editorial da revista.

A Comissão Editorial tem se empenhado em observar com rigor os critérios científicos que norteiam o processo editorial, ao mesmo tempo em que mantém o respeito à diversidade de temas e abordagens teórico-metodológicas que caracterizam o campo da Psicologia.

Ao investir com tal zelo na divulgação do conhecimento, este número contribui para a produção do salto qualitativo da Psicologia no cenário brasileiro.

Salientamos que temos contado com a disponibilidade e contribuição generosa dos pareceristas ad hoc que se incumbem da análise dos artigos submetidos. Essa contribuição tem se revelado crucial para o aprimoramento da qualidade dos manuscritos. Não se pode deixar de mencionar que trabalhos devolvidos aos autores, por não terem sido aprovados em uma primeira instância avaliativa, tem sido reescritos seguindo as sugestões oferecidas e, em seguida, submetidos novamente à apreciação.

Seguem-se os nove artigos, divididos em sessão teórica, com cinco trabalhos, e a de pesquisa empírica, com quatro artigos.

O conjunto de Pesquisas Teóricas que compõem este número da Paidéia é aberto com o artigo Preparação psicológica para admissão hospitalar de crianças: uma breve revisão, da autoria de Fernanda Nascimento Pereira Doca e Áderson Luiz Costa Junior, da Universidade de Brasília (UnB). Esse trabalho aborda um tema de interesse de pesquisadores em psicologia da saúde e da psicologia pediátrica 
que atuam junto a pacientes e familiares expostos à experiência de hospitalização. São mencionados técnicas e procedimentos aplicados nesse contexto e destacados os princípios metodológicos que norteiam o planejamento e a execução da intervenção, visando atenuar as condições potencialmente estressantes, aumentar os índices de adesão ao tratamento e otimizar estratégias mais eficientes de enfrentamento. $\mathrm{O}$ estudo apresenta ainda um modelo de programa de preparação psicológica para admissão hospitalar infantil.

$\mathrm{Na}$ seqüência, o artigo Sentido de número na infância: uma interconexão dinâmica entre conceitos e procedimentos, de Heloiza Helena de Jesus Barbosa, da Universidade Federal de Santa Catarina (UFSC), apresenta uma revisão bibliográfica sobre os processos cognitivos de desenvolvimento envolvidos na conceituação de número pela criança. Ainda que o debate entre as principais orientações dominantes nesse campo seja inconclusivo, os estudos revisados sugerem uma interconexão entre conceitos e procedimentos no processo de construção do sentido de número.

$\mathrm{O}$ artigo "A querela dos direitos": loucos, doentes mentais e portadores de transtornos $e$ sofrimentos mentais, de Rafael De Tilio, da Universidade de São Paulo, Ribeirão Preto, trata da questão dos direitos básicos dos portadores de sofrimento mental. Mostra o descompasso existente entre a atual concepção preconizada pela reforma psiquiátrica e a legislação brasileira, que ainda os qualifica como incapazes e periculosos. Desse modo, são colocados em foco os conflitos entre as concepções reformistas e os Códigos Civil e Penal brasileiros, com o intuito de contribuir com a reestruturação dos códigos legais e das práticas assistenciais, de modo a assegurar a plenitude dos direitos de cidadania dos usuários das instituições de saúde mental.

Em $A$ persuasão e o dinamismo psíquico em sermões de Antônio Vieira, Sandro Gontijo e Marina Massimi, da Universidade de São Paulo, Ribeirão
Preto, apresentam uma reflexão original assentada no tema da persuasão, que no decorrer do século XVII foi explorado pela oratória religiosa, mais especificamente a dos jesuítas, influente ordem religiosa a qual pertenceu o Padre Antônio Vieira. Os autores postulam que o estudo dessa oratória proporciona um modelo explicativo do psiquismo humano e propõem um mecanismo de intervenção no universo psíquico mediante o recurso da palavra, via retórica aristotélica. $\mathrm{O}$ artigo busca evidenciar a psicologia filosófica dos jesuítas que fundamenta a estratégia persuasiva, o que traz insumos para que se compreenda também a concepção de homem estabelecida no período histórico sob investigação.

Em $A$ intencionalidade da consciência no processo educativo segundo Paulo Freire, Paulo César de Oliveira, da Universidade Federal de São João Del Rei, e Patricia de Carvalho, daUniversidade Vale do Rio Verde, abordam a questão da intencionalidade da consciência no processo educativo, com o objetivo de explicitar as condições necessárias para que o processo de conscientização seja alcançado. Utilizando-se de uma revisão da obra de Paulo Freire, a autora mostra que existe uma relação de profunda dependência entre o processo de conscientização, o processo educacional e o processo concreto de libertação do homem.

Iniciando o bloco de Pesquisas Empíricas, o artigo Importância e domínios de avaliação psicológica: um estudo com alunos de Psicologia, da autoria de Ana Paula Porto Noronha, Maiana Farias Oliveira Nunes e Rodolfo Augusto Matteo Ambiel, da Universidade São Francisco, relata os resultados de uma pesquisa que investigou a importância conferida e a percepção de domínio de estudantes de Psicologia quanto a competências de avaliação psicológica. Baseando-se nas definições das competências essenciais apontadas pela American Psychological Association, foi aplicado um 
questionário que abordava temas, tais como o conhecimento de construtos psicológicos e saber utilizar e interpretar testes.

$\mathrm{O}$ artigo Atitudes de leitura e desesperança em idosos, da autoria de Katya Luciane de Oliveira e Mirian Cruvinel, da Universidade Estadual de Campinas (UNICAMP), buscou verificar a relação entre atitudes positivas e negativas em leitura e desesperança em idosos de um centro de terceira idade, de um posto de retirada de medicamentos e de uma instituição asilar. Os resultados evidenciaram relação estatisticamente significativa entre a pontuação na escala de atitudes de leitura e o nível de desesperança nos idosos, avaliado por intermédio da Escala de Desesperança de Beck.

Em Percepção de padrões concêntricos em crianças de 8 a 13 anos, Natanael Antonio dos Santos, Valtenice de Cássia Rodrigues de Matos França e Éllen Dias Nicácio da Cruz, da Universidade Federal da Paraíba(UFPB), propuseram-se a mensurar a função de sensibilidade ao contraste de padrões circulares concêntricos com diferentes freqüências radiais em crianças e jovens adultos. Os resultados mostraram que as curvas das crianças melhoram progressivamente e de forma significativa com o avanço da idade.

No artigo $A$ mãe, o filho e a sindrome de Down, Thais Helena Andrade Machado Couto, Miriam Tachibana e Tania Maria José Aiello-Vaisberg, da Pontifícia Universidade Católica de Campinas (PUCCamp), investigaram as experiências de mães na criação e educação de filhos com síndrome de Down, a partir de um ponto de vista psicanalítico. Foram realizadas entrevistas abertas com mães e, após cada encontro, foram redigidas narrativas psicanalíticas que permitiram apreender os campos psicológico-vivenciais. Os resultados indicaram que as mães desenvolveram diversas estratégias de sobrevivência emocional, que lhes permitiram manterem-se por um tempo prolongado no estado de preocupação materna primária especial. As autoras consideram que esse estudo traz contribuições relevantes para o planejamento de dispositivos assistenciais, sugerindo a necessidade de um maior conhecimento dos psicodinamismos maternos para que se obtenha o envolvimento familiar no contexto do atendimento às necessidades do portador de síndrome de Down.

Finalmente, apresenta-se a resenha do livro Pedagogia(s) da infância: dialogando com o passado: construindo o futuro, da autoria de Júlia Oliveira-Formosinho, Tizuko Morchida Kishimoto e Mônica Appezzato Pinazza, da Universidade de São Paulo, Ribeirão Preto. Essa resenha foi organizada por Marmeide de Oliveira Gomes e Amabille Silva Paschoim, que salientam as contribuições mais significativas da obra para a história da educação e da educação infantil.

Este número da Paidéia se encerra como os demais, com Notícias de Congressos e as Normas de Publicação.

Esperamos que os leitores possam sair enriquecidos da aventura da leitura e que, ao final dessa empreitada, sintam-se também estimulados a submeterem suas próprias contribuições à Paidéia.

Manoel Antônio dos Santos 